\title{
Doping effect of viologen on photoconductive device made of poly ( $p$-phenylenevinylene)
}

\author{
J. Y. Park, ${ }^{\text {a) }}$ S. B. Lee, ${ }^{\text {b) }}$ Y. S. Park, and Y. W. Park \\ Department of Physics and Condensed Matter Research Institute, Seoul National University, \\ Seoul 151-742, Korea \\ C. H. Lee \\ Department of Physics, Inha University, Inchon 402-751, Korea \\ J. I. Lee and H. K. Shim \\ Department of Chemistry, KAIST, Taejon 305-701, Korea
}

(Received 20 January 1998; accepted for publication 2 April 1998)

\begin{abstract}
We report the photovoltaic properties of the donor-acceptor composite system of poly ( $p$-phenylenevinylene) (PPV) and viologen. We observed the significant enhancement of photocurrent with increasing the doping ratio of viologen. The maximum photocurrent of viologen-doped PPV was nine times as high as that of the pristine PPV. The maximum quantum yield and photosensitivity are $13 \%$ (electron/photon) and $0.05 \mathrm{~A} / \mathrm{W}$, respectively, at low bias voltage $(-2 \mathrm{~V})$. The increase of photocurrent is explained with the efficient charge separation that resulted from the transfer of photoexcited electrons from PPV to viologen. The mixture of PPV and viologen can be used as a sensitive photodiode material. (c) 1998 American Institute of Physics.
\end{abstract} [S0003-6951(98)04122-9]

Polymer photodiodes and photovoltaic cells based on polymer composites with internal donor/acceptor heterojunctions are of active interest. ${ }^{1-4}$ Since the discovery of efficient photoinduced charge transfer between conducting polymers and buckminsterfullerene $\left(\mathrm{C}_{60}\right)$, a number of experiments have been done with these compositions for the application as a sensitive photodetector. ${ }^{5-8}$ The separation of photogenerated species is known to be more probable at the interface between molecular semiconducting materials of different electronegativity and electron affinity. ${ }^{9}$

In this article, we report efficient photoinduced charge transfer between poly ( $p$-phenylenevinylene (PPV) and viologen. We observed the significant enhancement of photocurrent in diode structure formed with thin films of the PPV:viologen composite, sandwiched between $\mathrm{Al}$ and indium tin oxide (ITO) electrodes.

Viologen is a well-known material as an electron acceptor in photosynthesis and photochemistry. ${ }^{10}$ It shows very long lifetime in photoinduced charge-separated state and forms charge-transfer (CT) complexes with a wide variety of organic electron donors such as 2,6-dimethoxynaphthalene, bromide and iodide, etc. ${ }^{11}$ Until now, most experiments on the CT system with viologen were done in solution state. Usually, the formation of CT complexes is accompanied by the spontaneous development of a new color. ${ }^{12}$ In spite of good properties of viologen as an electron acceptor, few works have been done on the composite system of viologen and conducting polymers. Supposing that the PPV and viologen can form an intermolecular donor-acceptor CT com-

${ }^{a)}$ Electronic mail: ywpark@plaza.snu.ac.kr

${ }^{b}$ Permanent address: Heat Physics Department, Uzbek Academy of Sciences, Chilanzar-C, Katartal 28, Tashkent 700135, Uzbekistan. plex, the photoresponse would be enhanced in the PPV:viologen system.

PPV was synthesized through the sulfonium precursor route. ${ }^{13}$ The ethyl viologen dibromide was purchased from Aldrich Company and mixed with PPV-precursor polymer in common solvent (methanol). The solubility of viologen was good so that we were able to make optical quality thin film. The molecular weight percent of viologen was changed as $0 \%, 10 \%, 25 \%$, and $30 \%$. The chemical structures of the PPV and ethyl viologen dibromide are shown in Fig. 1.

The composite films were deposited on top of an ITO substrate by spin coating and then heated for two hours in vacuo at $250{ }^{\circ} \mathrm{C}$ for conversion of the precursor to PPV. The thickness of the spin cast films was $\sim 2000 \AA$. Al electrodes (thickness $=600 \AA$, size $=1 \mathrm{~mm}^{2}$ ) were thermally evaporated onto the film.

The electrical characterization of the diode was done under vacuum of about $10^{-3}$ Torr. For the measurement of the photocurrent action spectra of cells, we used a monochromatic light from a $500 \mathrm{~W}$ Xenon arc lamp. The irradiation was made from the ITO side. At each wavelength step (1 $\mathrm{nm}$ ), the intensity of light was calibrated by a calibrated Siphotodiode. For the optical absorption measurements, we used Bechman DU-70 spectrophotometer.

Figure 2(a) shows the spectral dependence of photocurrent under the reverse bias of $-2.0 \mathrm{~V}$, for four diodes with different concentrations of viologen. The optical absorption spectrum of PPV2 (25\% of viologen) is also plotted for comparison. Figure 2(b) shows the photocurrent action spectra of $\mathrm{Al} / \mathrm{PPV} 2 / \mathrm{ITO}$ cell at -2.0 and $4.0 \mathrm{~V}$ biases. Inset in Fig. 2(b) shows a short circuit photocurrent spectrum. Under the forward bias, the device shows a similar action spectrum with that of the reverse bias.

The photocurrent responses in Fig. 2 are antibatic as 


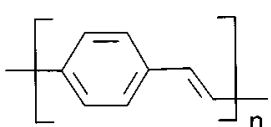

PPV

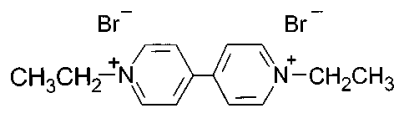

Viologen
FIG. 1. Chemical structure of PPV and ethyl viologen dibromide.

reported before; ${ }^{14,15}$ the maximum of photocurrent action spectra is located at the photon energy $(\sim 2.4 \mathrm{eV})$ where the optical absorption is very weak. The spectral response shows a maximum at a photon energy that balances the competing factors of the absorbed light intensity and the position of photocarrier generation with respect to the collecting electrodes. ${ }^{15}$ Since the photocurrent peak near $2.4 \mathrm{eV}$ is very sharp with the full width at half maximum as small as $19 \mathrm{~nm}$ $(0.085 \mathrm{eV})$, microcavity effect may also be operative in the spectral response although the reflectivity of the ITO/glass interface is low. The resonance excitation energy of $2.4 \mathrm{eV}$ $(516 \mathrm{~nm})$ can correspond to the third harmonic microcavity mode for the cell thickness of about $2000 \AA^{16}$

Mulliken observed new absorption bands in TCNBmethyl viologen complex solution system. ${ }^{17} \mathrm{He}$ proposed that they are due to charge-transfer transition in the ground state, i.e., light absorption causes an electron transfer from the donor to the acceptor moiety of the complex, and the excited electronic state may be described as a chargeseparated or ion-pair state. However, the optical absorption
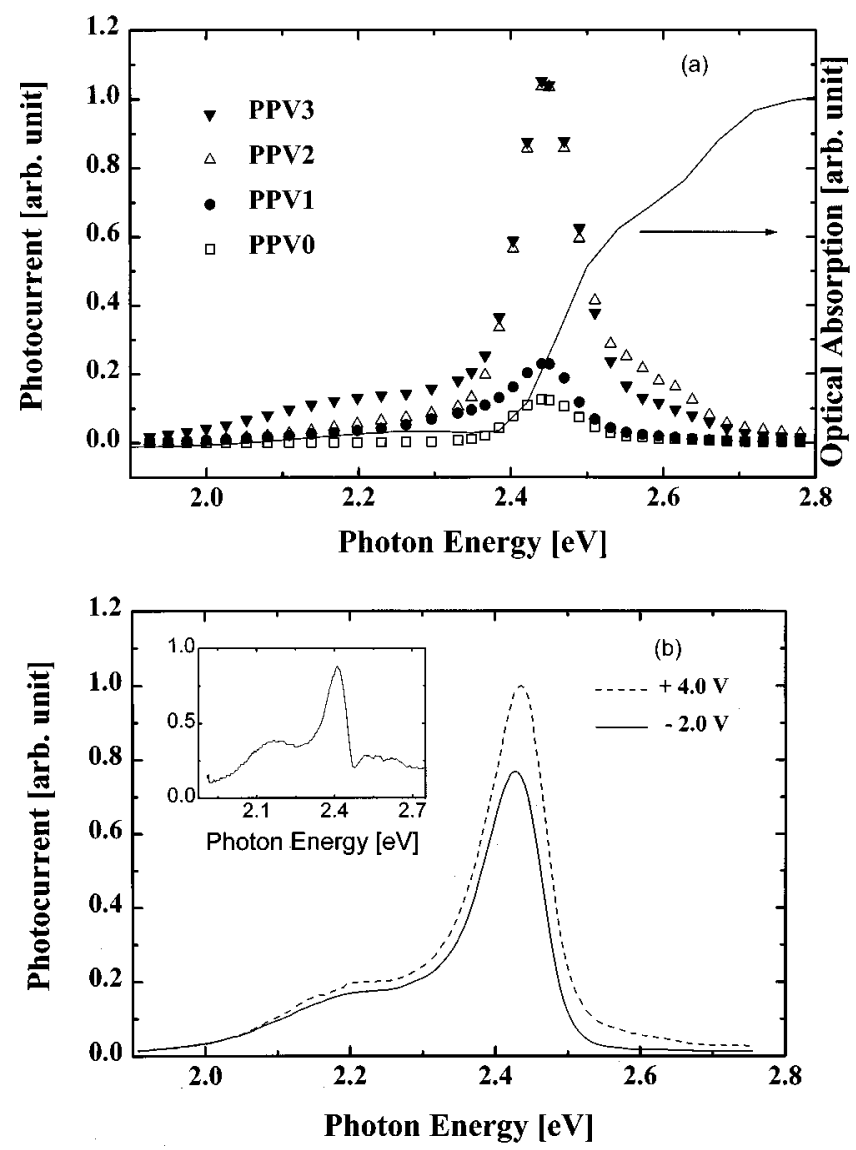

FIG. 2. (a) Photocurrent action spectra and optical absorption of PPV with various doping concentrations of viologen. (The doping concentrations of viologen in PPV0, PPV1, PPV2, and PPV3 are 0\%, 10\%, 25\%, and 30\%, respectively.) (b) Photocurrent action spectra of A1/PPV2/ITO cell at differ-

ent biases. Inset shows a short circuit photocurrent spectrum. under monochromatic illumination with the intensity of 20
Downloaded 09 Nov 2009 to 147.46.118.89. Redistribution subject to AIP license or copyright; see http://apl.aip.org/apl/copyright.jsp

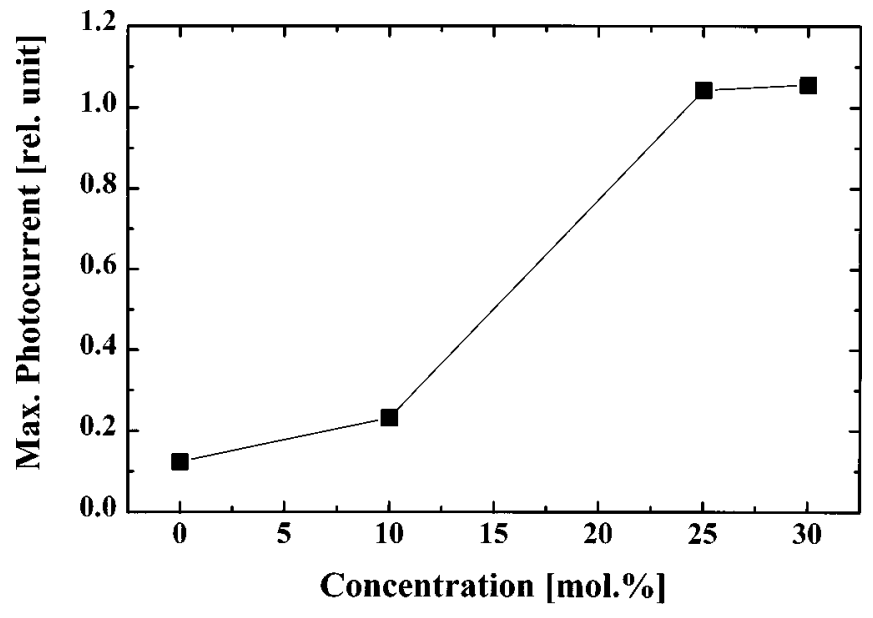

FIG. 3. Maximum photocurrent at $508 \mathrm{~nm}$ vs doping concentration of viologen.

spectra of viologen doped PPV, shown in Fig. 2(a), are similar to those of the pristine PPV. This implies that there is no charge transfer between PPV and viologen in the ground state.

Another important feature of the PPV:viologen complex system present in Fig. 2 is the shoulder at $2.18 \mathrm{eV}$. This feature can be more clearly resolved in the inset of Fig. 2(b). We can assign this band to the reduced ethyl viologen (EV). Our proposed mechanism is the following: upon photoexcitation the reduction of EV occurs due to electron transfer from photoexcited intrachain exciton in the polymer chain to viologen according to the reaction:

$$
\mathrm{EV}^{2+}+e^{-} \rightarrow \mathrm{EV}^{+}
$$

After the reduction step, the reverse formation of $\mathrm{EV}^{2+} \mathrm{di}$ cation can take place. We know from the spectroelectrochemical study of a series of symmetrical 1,1-dialkyl-4,4bipyridiliums that all viologens show absorption bands at $600 \mathrm{~nm}$ for the monomeric radical cation and at $550 \mathrm{~nm}$ for the dimer. ${ }^{18}$ The dimer formation is more favorable at the relatively higher concentration of viologens. We observed $\sim 35 \%$ quenching of photoluminescence with the doping of viologens to PPV, in support of our model.

In the $30 \%$ viologen-doped cell (PPV3), the maximum photocurrent is about nine times higher than that of the pristine PPV cell. The photocurrent and absolute photosensitivity of the PPV3 cell are calculated as about $1 \times 10^{-6} \mathrm{~A} / \mathrm{cm}^{2}$ and $0.05 \mathrm{~A} / \mathrm{W}$ at $-2 \mathrm{~V}$ under the photoexcitation of $20 \mathrm{~mW} / \mathrm{cm}^{2}$, corresponding to the quantum yield of $\sim 13 \%$ (electrons/photons). This photosensitivity is comparable to that reported by $\mathrm{Yu}$ et al. in the ITO/MEH-PPV: $\mathrm{C}_{60} / \mathrm{Ca}$ devices. ${ }^{2}$

The photocurrent was remarkably enhanced as the concentration of viologen was increased. Figure 3 shows the maximum photocurrent at $508 \mathrm{~nm}(2.44 \mathrm{eV})$ versus the concentration of viologen. It shows a saturation over $25 \%$ of the viologen concentration. Similar saturation behavior was also reported in the photoconductivity of the MEH-PPV: $\mathrm{C}_{60}$ composite system. ${ }^{19}$

Figure 4 shows the current-voltage $(I-V)$ characteristics of an ITO/PPV:viologen(25\%)/Al device in the dark and under monochromatic illumination with the intensity of 20 AIP license or copyright; see http://apl.aip.org/apl/copyright.jsp 


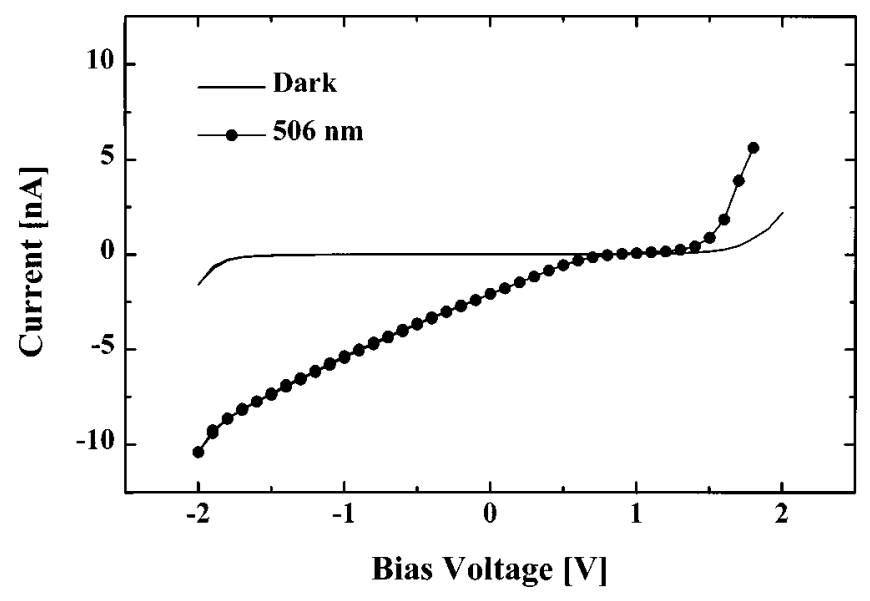

FIG. 4. $I-V$ characteristics of PPV2 (25\% of viologen doping) under dark and light illumination.

$\mu \mathrm{W} / \mathrm{cm}^{2}$ at $506 \mathrm{~nm}$. This device shows good photoresponsive properties under illumination, developing an opencircuit voltage $\left(V_{\mathrm{oc}}\right)$ and short-circuit current $\left(I_{\mathrm{sc}}\right)$ approaching $0.8 \mathrm{~V}$ and $-0.21 \times 10^{-6} \mathrm{~A} / \mathrm{cm}^{2}$, respectively. The fill factor, defined as $(I \times V)_{\max } /\left(I_{\mathrm{sc}} \times V_{\mathrm{oc}}\right)$, where $(I \times V)_{\max }$ is the maximum power rectangle, is calculated as 0.2 and a power conversion efficiency of $\sim 0.17 \%$. As expected, a significant increase in both forward and reverse bias current is observed, resulting from photoinduced charge dissociation at the interfaces of PPV and viologen. The increase in the current by nearly three orders of magnitude upon illumination at $-1 \mathrm{~V}$, demonstrates that the PPV:viologen diode may serve as a relatively sensitive photosensor which operates under low bias voltage.

Morita et al. compared the energies of the lowest unoccupied states of $\mathrm{C}_{60}$ with the energies of the highest occupied state of semiconducting polymers and suggested that the partial charge transfer (CT) can occur in the ground state. ${ }^{6}$ However, there is no new absorption band associated with the CT transition in our composite system. Moreover, the $I-V$ characteristics of our device (Fig. 4) show that the charge dissociation can be just photoinduced with high efficiency, although the charge transfer between the donor and acceptor does not occur in the ground state.

In summary, we have studied photodiodes fabricated with the composite system of PPV and ethyl viologen. The photodiodes made of these materials have shown nine times higher photosensitivity than that made of the pristine PPV.
The photosensitivity is also comparable with that of conducting polymer- $\mathrm{C}_{60}$ composite system. These results show that viologens can also be used as a promising electron acceptor like $\mathrm{C}_{60}$ in thin film devices of the conducting polymer composites. In addition, the observed photoresponse at low energy $(\sim 2.4 \mathrm{eV})$ below absorption edge of PPV is a very important feature of viologen-doped PPV polymers which opens a way of using this system in resonant cavity enhanced photonic devices. Especially, in the sense of price for synthesis, viologens can be a competitive material with $\mathrm{C}_{60}$. Investigation on the well designed metal mirror microcavity structure is now in progress.

This work was jointly supported by the Korea Science and Engineering Foundation (KOSEF) and by the Ministry of Education (MOE), Korea though the Basic Science Research Institute of Seoul National University.

${ }^{1}$ G. Yu and A. J. Heeger, J. Appl. Phys. 78, 4510 (1995).

${ }^{2}$ G. Yu, J. Gao, J. C. Hummelen, F. Wudl, and A. J. Heeger, Science 270, 1789 (1995).

${ }^{3}$ J. J. M. Halls, C. A. Walsh, N. C. Greenham, E. A. Marseglia, R. H. Friend, S. C. Moratti, and A. B. Holmes, Nature (London) 376, 498 (1995).

${ }^{4}$ J. Y. Park, H. M. Le, G. T. Kim, H. Park, Y. W. Park, I. N. Kang, D. H. Whang, and H. K. Shim, Synth. Met. 79, 177 (1996).

${ }^{5}$ N. S. Sariciftci, L. Smilowitz, A. J. Heeger, and F. Wudl, Science 258, 1474 (1992).

${ }^{6}$ S. Morita, A. A. Zakhidov, and K. Yoshino, Solid State Commun. 82, 249 (1992).

${ }^{7}$ B. Kraabel, C. H. Lee, D. McBranch, D. Moses, and A. J. Heeger, Chem. Phys. Lett. 213, 389 (1993).

${ }^{8}$ N. S. Sariciftci, D. Braun, C. Zhang, V. I. Srdanov, A. J. Heeger, G. Stucky, and F. Wudl, Appl. Phys. Lett. 62, 585 (1993).

${ }^{9}$ C. W. Tang, Appl. Phys. Lett. 48, 183 (1986).

${ }^{10}$ S. Baral-Tosh, S. K. Chattopadhyay, and P. K. Das, J. Am. Chem. Soc. 88, 1404 (1984), and references therein.

${ }^{11}$ K. B. Yoon and J. K. Kochi, J. Phys. Chem. 95, 3780 (1991), and references therein.

${ }^{12}$ S. M. Hubig and J. K. Kochi, J. Phys. Chem. 99, 17578 (1995).

${ }^{13}$ A. O. Patil, S. D. D. V. Rughooputh, and F. Wudl, Synth. Met. 29, E115 (1989).

${ }^{14}$ G. Harrison, J. Gruner, and G. C. W. Spencer, Phys. Rev. B 55, 7831 (1997).

${ }^{15}$ R. N. Marks, J. J. M. Halls, D. D. C. Bradley, R. H. Friend, and A. B. Holmes, J. Phys.: Condens. Matter 6, 1379 (1994).

${ }^{16}$ V. Cimrova and D. Neher, J. Appl. Phys. 79, 3299 (1996).

${ }^{17}$ R. S. Mulliken and W. B. Person, Molecular Complexes (Wiley, New York, 1969).

${ }^{18}$ E. M. Kosower and J. L. Cotter, J. Am. Chem. Soc. 86, 5524 (1964).

${ }^{19}$ C. H. Lee, G. Yu, D. Moses, K. Pakbaz, C. Zhang, N. S. Sariciftci, and A. J. Heeger, Phys. Rev. B 48, 15425 (1993). 